\title{
Controle Químico da Ferrugem Asiática (Phakopsora pachyrhizi Sidow) na cultura da soja
}

\author{
Lucas Navarini, Leandro José Dallagnol, Ricardo Silverio Balardin, \\ Marcelo Temp Moreira, Rosana Ceolin Meneghetti, Marcelo Gripa Madalosso
}

Departamento de Defesa Fitossanitária, Centro de Ciências Rurais, Universidade Federal de Santa Maria, C.P. 5025, CEP 97111-970. Santa

Maria-RS. e-mail: navarini@gmail.com.

Autor para correspondência: Lucas Navarini

Data de chegada: 29/03/2005. Aceito para publicação em: 10/10/2006.

\section{RESUMO}

Navarini, L, Dallagnol,L.J., Balardin, R.S., Moreira, M.T., Meneghetti, R.C., Madolosso, M.G. Controle químico da ferrugem asiática (Phakopsora pachyrhizi Sydow) na cultura da soja. Summa Phytopathologica, v.33, n.2, p.182-186, 2007.

A eficiência de diferentes doses de fungicidas aplicados em diversos estádios fenológicos da soja foi avaliada no controle de Phakopsora pachyrhizi. As cultivares de soja utilizadas nos experimentos foram RS 10, BRS 154, CD 201, BRS 153, CD 206 e CD 209, sendo conduzidos em condições de campo sob infecção natural do patógeno. Os resultados obtidos demonstraram variação significativa no rendimento quando duas aplicações de fungicidas foram realizadas. A seqüência de fungicidas utilizados bem como o inóculo presente na área experimental evidenciaram a eficácia de controle da ferrugem. Fungicidas do grupo das estrobirulinas aplicados no estádio $\mathrm{R}_{1}$ apresentaram o melhor desempenho, e o controle executado preventivamente possibilitou a maior efetividade.

Palavras-chaves adicionais: Estrobirulinas, estádios fenológicos, preventivo.

\begin{abstract}
Navarini, L, Dallagnol,L.J., Balardin, R.S., Moreira, M.T., Meneghetti, R.C., Madalosso, M.G. Chemical Control of Soybean Rust (Phakopsora pachyrhizi Sidow) in soybean crop. Summa Phytopathologica, v.33, n.2, p.182-186, 2007.

The efficiency of different fungicides rates applied at various soybean stages was evaluated to control Phakopsora pachyrhizi. Soybean cultivars used in the field trials under natural infection were: RS 10, BRS 154, CD 201, BRS 153, CD 206 and CD 209. Results showed significant variation on yield after two fungicide applications.

The sequence of fungicides and the inoculum level at the experimental area were important to establish the efficacy of fungicides in the control of the disease. Strobirulins applied at $\mathrm{R}_{1}$ growth stage had the best performance and the preventative control resulted in the highest efficacy.
\end{abstract}

Additional keywords: Strobirulins, host growth stages, preventative control.

A ferrugem asiática, causada pelo fungo Phakopsora pachyrhizi Sydow, tem causado danos significativos nas lavouras de soja. Segundo Caldwell \& Laing (5), o inóculo chegou ao continente africano transportado por correntes aéreas. Na América do Sul foi descrita pela primeira vez no Paraguai por Morel (11), seguido do Brasil, Yorinori (18), Uruguai, Argentina e Bolívia. Os danos no rendimento têm variado entre 10 e $75 \%$, principalmente em áreas onde o controle não é executado ou o é de forma tardia.

Os sintomas são particularmente evidentes nas folhas, evoluindo desde urédias isoladas à áreas com pronunciada coalescência quando provoca amarelecimento e prematura abscisão foliar. São agrupados em lesões de coloração bronzeada com duas a cinco urédias e esporulação abundante (B) ou formando lesões pardo-avermelhadas, com zero a duas urédias e esporulação esparsa (PA) (3).

Molhamento foliar prolongado $(10 \mathrm{~h} / \mathrm{dia})$, temperatura noturna entre 18 e $24^{\circ} \mathrm{C}$, e chuvas freqüentes mostram-se como condições determinantes para o estabelecimento da doença. A dispersão da doença tem ocorrido a uma taxa superior a $1 \mathrm{~m} /$ dia (15). Segundo Bromfield (3) as infecções no início do florescimento produzem elevados níveis de dano, afetando também o teor de proteína no grão (12).
A destruição de hospedeiros secundários, semeadura antecipada de cultivares de ciclo precoce são medidas de controle que propiciam redução na pressão de inóculo e contribuem para aumento na eficiência do controle químico. Cultivares resistentes não se encontram indicadas comercialmente tornando o controle químico a alternativa mais eficaz de controle desta doença.

Fungicidas aplicados de forma preventiva tem se destacado como a estratégia mais eficaz no controle desta doença $(1,9)$. Maior período residual e melhor desempenho dos fungicidas foram obtidos por Vitti et al. (20) devido à aplicação preventiva de fungicidas. Da mesma forma, Oliveira (13) observou aumento no rendimento de até $100 \%$ quando realizou o controle da doença preventivamente. $\mathrm{O}$ objetivo deste trabalho foi avaliar a consistência de programas de controle químico aplicados de forma curativa e preventiva em várias cultivares de soja e diferentes estádios fenológicos da cultura.

\section{MATERIAL E MÉTODOS}

Os experimentos foram conduzidos na safra 2002-2003 e as cultivares de soja implantadas e conduzidas segundo as Indicações 
Técnicas para a cultura da soja (15). Os experimentos foram instalados com um tratamento testemunha sem aplicação de fungicidas e um tratamento chamado controle total, que consistiu na pulverização quinzenal de diferentes ingredientes ativos desde o estádio R1 (primeiro botão floral na altura do quarto nó da haste principal).

Os fungicidas foram aplicados com barra provida de quatro pontas tipo leque (Teejet XR 110.02), acoplada a um pulverizador costal pressurizado a $\mathrm{CO}_{2}$ e regulado a pressão de trabalho de $30 \mathrm{lbs} \cdot \mathrm{pol}^{-2}$. A velocidade de deslocamento utilizada na aplicação dos fungicidas foi de $1 \mathrm{~m} \cdot \mathrm{s}^{-1}$ e o volume da calda ajustado para $150 \mathrm{~L} \cdot \mathrm{ha}^{-1}$. As parcelas experimentais apresentaram área total de $13,5 \mathrm{~m}^{2}(2,7 \mathrm{x} 5,0 \mathrm{~m})$ sendo que todas as avaliações foram realizadas na área útil de 7,2 $\mathrm{m}^{2}(1,8 \mathrm{x}$ $4,0 \mathrm{~m})$.

No experimento 1 foram utilizados os cultivares de soja RS 10, BRS 154, CD 201, BRS 153, CD 206, CD 209, sendo que os momentos de aplicação e os programas de controle são discriminados na Tabela 1 .

Neste experimento foram avaliados o número de pústulas. $\mathrm{cm}^{-2} \mathrm{e} \mathrm{o}$ rendimento de grãos da soja $\left(\mathrm{kg} \cdot \mathrm{ha}^{-1}\right)$. O número de pústulas por $\mathrm{cm}^{2}$ foi obtido a partir da observação de dez folíolos amostrados aleatoriamente no terço médio e superior de plantas localizadas na área útil da parcela experimental de todas as repetições de cada tratamento. Em cada folha foram aleatoriamente marcados três pontos com $1 \mathrm{~cm}^{2}$. Cada uma das áreas foi fotografada com câmara digital e aumento de $60 \mathrm{x}$ com resolução de $2080 \times 1560$ pixels, com o que foi realizada a contagem do número de pústulas. Devido à rapidez do processo de fotografia, as urédias apresentaram qualidade semelhante para avaliação.

No experimento 2 foram utilizados os cultivares de soja RS 10 e
BRS 154. No cultivar RS 10 os tratamentos foram aplicados de forma curativa com aplicações iniciadas quando as plantas apresentavam 3\% de severidade de ferrugem asiática, esse momento correspondeu ao estádio R5.2. No cultivar BRS 154, os tratamentos foram aplicados preventivamente, na ausência completa de sintomas no estádio R4, os programas testados estão apresentados na Tabela 1 .

Nesse experimento foram avaliados a severidade da doença, área foliar verde remanescente, percentual de desfolha e rendimento de grãos. A severidade da ferrugem foi obtida a partir da observação visual dos sintomas em quatro pontos da área útil da parcela experimental considerando o terço superior e inferior das plantas na avaliação. Os resultados apresentados consideram os dados da segunda avaliação, 15 e 25 dias após a aplicação do último tratamento, já que na primeira avaliação não foi observado diferença significativa entre os tratamentos testados, mesmo que tenham variado em relação ao tratamento testemunha.

Os componentes de área foliar verde e desfolha foram avaliados no estádio $\mathrm{R}_{6}$. Foram considerados plantas em quatro pontos aleatórios da área útil da parcela experimental. A área foliar verde e a desfolha foram determinadas com relação ao controle total.

Em ambos os experimentos o rendimento de grãos foi obtido de todas as plantas da área útil da parcela experimental, sendo as plantas cortadas, trilhadas e a massa de grãos submetida a uma pré-limpeza. $\mathrm{O}$ volume total de grãos foi pesado e determinado a umidade, posteriormente ajustada a $13 \%$ para o cálculo do rendimento final em $\mathrm{kg} / \mathrm{ha}$.

O delineamento experimental utilizado foi de blocos ao acaso com quatro repetições. Para análise dos dados foi utilizado o teste de Tukey $(\mathrm{pd}>0,05)$ para comparação múltipla das médias.

Tabela 1 - Programas de controle e doses aplicadas em cultivares de soja para controle de ferrugem asiática. Santa Maria/RS, 2005.

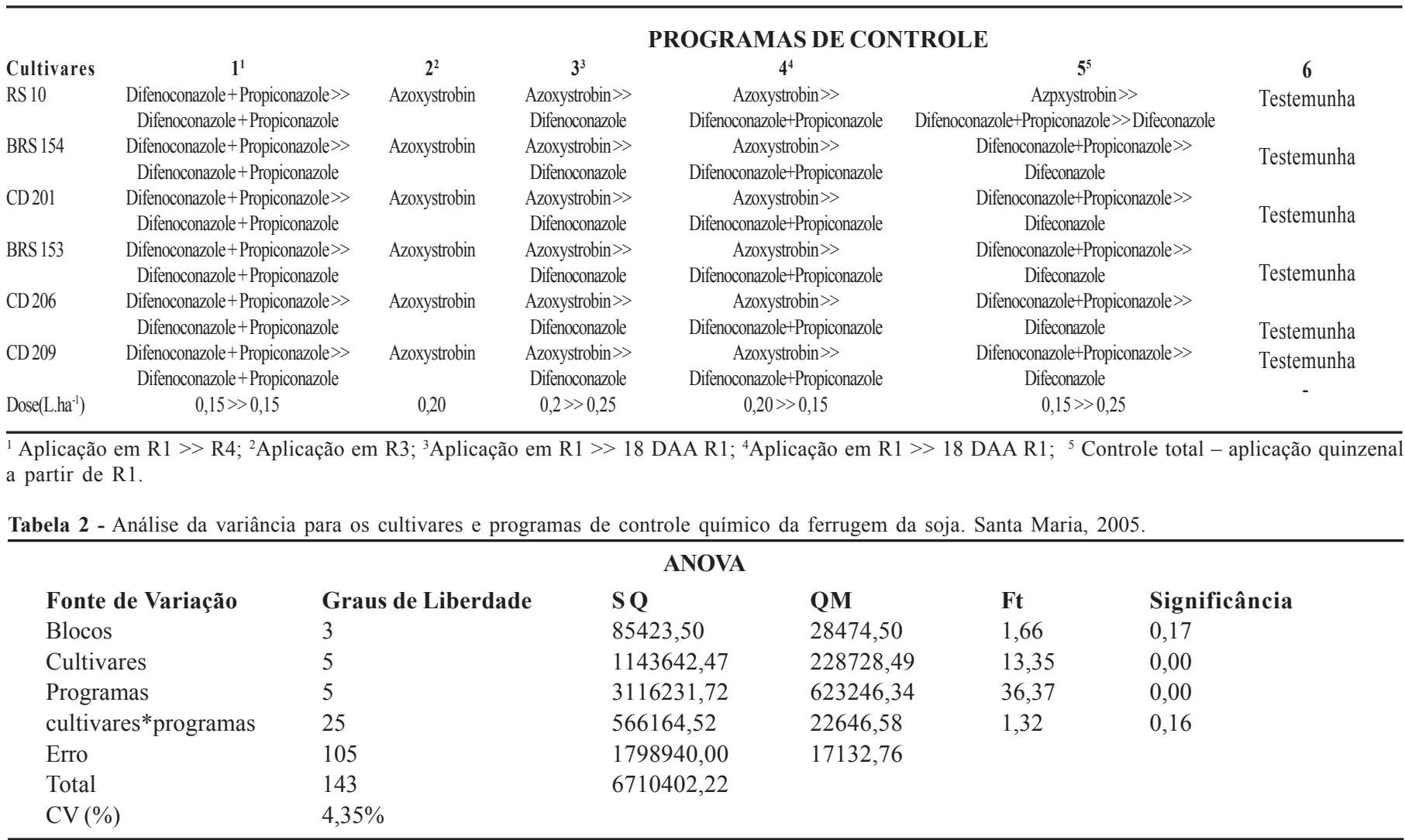


Tabela 3 - Número de pústulas.cm ${ }^{-2}$ de Phakopsora pachyrhizi avaliado em seis cultivares de soja submetidas a sete programas de controle químico. Santa Maria, 2005.

\section{Programas de controle}

\begin{tabular}{|c|c|c|c|c|c|c|c|c|c|c|c|c|c|}
\hline Cultivares & & & & & & & & & & & 6 & & CV (\%) \\
\hline BRS 154 & 4,6 & $\mathrm{c}$ & 6,8 & $\mathrm{~d}$ & 1,4 & $\mathrm{a}$ & 1,6 & $\mathrm{a}$ & 0,8 & $\mathrm{a}$ & 10,4 & $\mathrm{e}$ & 20,45 \\
\hline BRS 153 & 2,4 & $\mathrm{bc}$ & 6,6 & $\mathrm{~b}$ & 2,1 & $\mathrm{~b}$ & 1,9 & $a b$ & 0,7 & $\mathrm{a}$ & 20,1 & $\mathrm{e}$ & 18,43 \\
\hline CD 206 & 2,5 & $\mathrm{~b}$ & 7,3 & $\mathrm{c}$ & 2,4 & $\mathrm{~b}$ & 2,3 & $\mathrm{~b}$ & 0,8 & $\mathrm{a}$ & 10,9 & $\mathrm{~d}$ & 22,61 \\
\hline CD 209 & 2,5 & $\mathrm{bc}$ & 2,6 & $\mathrm{bc}$ & 0,7 & $\mathrm{a}$ & 1,3 & $a b$ & 0,3 & $\mathrm{a}$ & 9,5 & $\mathrm{e}$ & 34,85 \\
\hline
\end{tabular}

*Médias seguidas da mesma letra (linha) não diferem estatisticamente pelo teste de Tukey $(\mathrm{p}<0,05)$.

Tabela 4 - Rendimento de seis cultivares de soja, infectadas por Phakopsora pachyrhizi e submetidas a seis programas de controle químico. Santa Maria, 2005.

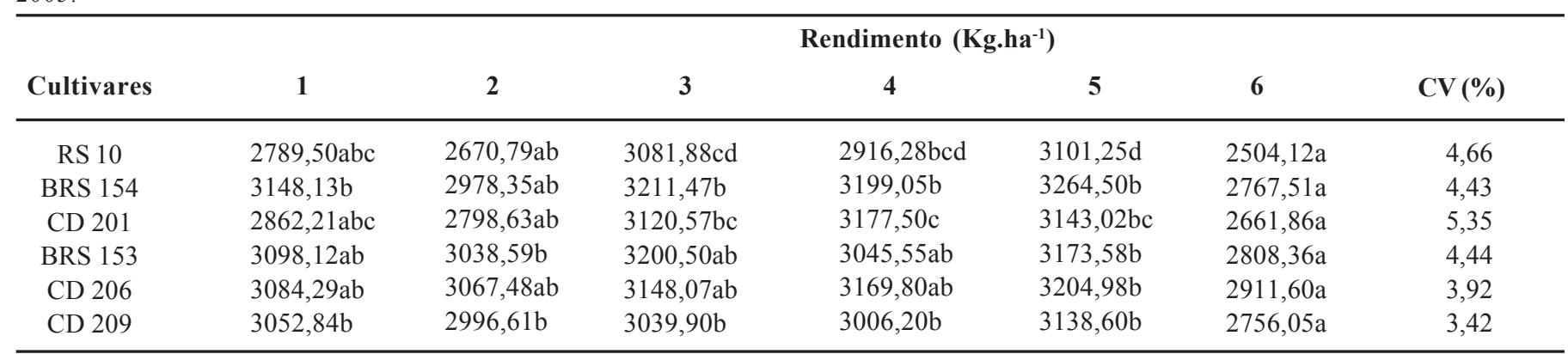

*Médias seguidas da mesma letra (linha) não diferem estatisticamente pelo teste de Tukey ( $<0,05)$.

Tabela 5 - Área foliar verde remanescente e rendimento de grãos das cultivares RS 10 e BRS 154 submetidas à aplicação curativa e preventiva de fungicidas para controle da ferrugem da soja. Santa Maria, 2005.

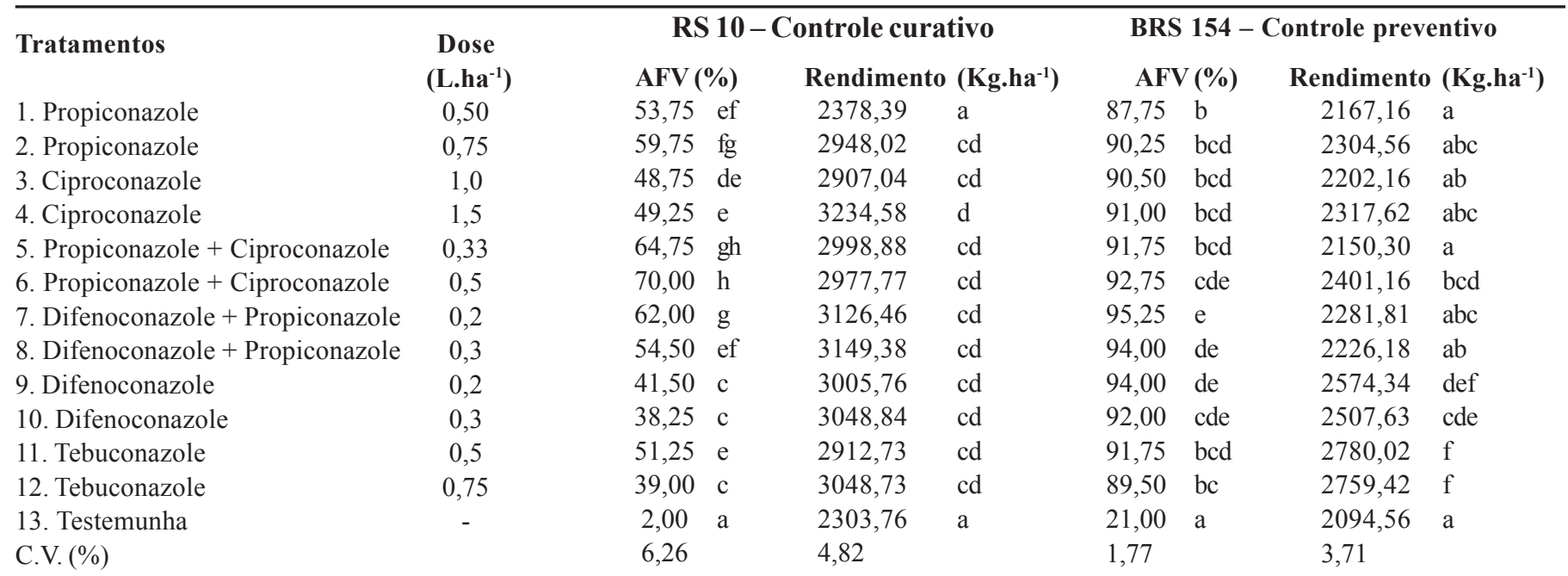

Médias seguidas da mesma letra (coluna) não diferem estatisticamente pelo teste de Tukey (pd<0,05).

\section{RESULTADOS E DISCUSSÃO}

Os dados obtidos demonstraram que a ferrugem da soja afetou significativamente o rendimento de grãos das cultivares de soja, com redução variável entre $10,0 \%$ e $40,4 \%$. A variação do rendimento foi influenciada pelo momento e pelo número de aplicações dos fungicidas. A interação entre cultivares e programas de controle químico não foi significativo à 5\% (Tabela 2).

$\mathrm{Na}$ Tabela 3 foi verificado que o número de pústulas. $\mathrm{cm}^{-2}$ diferiu em função do número de pulverizações. Quando foi realizada apenas uma aplicação de azoxystrobin no estádio $\mathrm{R}_{3}$, o número médio de pústulas foi de 5,58 pústulas.cm ${ }^{-2}$, enquanto que nos programas que incluíram duas aplicações, este número foi reduzido para 1,91 a 3,06 pústulas. $\mathrm{cm}^{-2}$. O melhor desempenho foi observado quando a primeira aplicação foi realizada com Azoxystrobin e a segunda aplicação com um triazol isolado ou em mistura de triazóis.

O maior período de proteção à planta, obtido com duas aplicações de fungicida, refletiu na menor severidade da doença, resultando nos maiores incrementos de rendimento (Tabela 4). A amplitude no aumento do rendimento de grãos com uma aplicação e duas aplicações foi de $5,1 \%$ a $8,1 \%$ e $8,1 \%$ a $23 \%$, respectivamente. Santos et al. (16); Moura et al. (10); Silva et al. (17) verificaram maior eficiência de controle 
quando realizadas duas aplicações de fungicida.

O cultivar CD 209 apresentou o menor número de pústulas. $\mathrm{cm}^{-2}$, seguido das cultivares CD 206 e BRS 154, tendo as cultivares RS 10 e BRS 153 apresentado o maior número de pústulas. $\mathrm{cm}^{-2}$, isso demonstra que mesmo na ausência de cultivares resistentes, há variação entre cultivares quanto à sensibilidade a $P$. pachyrhizi. Dallagnol et al. (6) ao testar a sensibilidade de 60 cultivares de soja a um isolado de $P$. pachyrhizi observou variação no número de pústulas desenvolvidas, quando a inoculação foi realizada em diferentes estádios de desenvolvimento, observando influência no período de incubação e na taxa de progresso da doença.

As variações nas doses dos fungicidas produziram efeito positivo somente para propiconazole, ciproconazole e propiconazole + ciproconazole, onde foi verificado um aumento na eficácia de controle devido ao aumento de dose. Por outro lado, difenoconazole + propiconazole, difenoconazole e tebuconazole não apresentaram variação na eficácia de controle devido ao aumento de dose. Bianchini et al. (2) também verificou aumento na eficácia de ciproconazole com aumento da dose, refletindo em maior produtividade.

Na Tabela 5 apresenta o resultado obtido com aplicação de diversos ingredientes ativos de fungicidas, de forma preventiva na cultivar BRS 154 e curativa na cultivar RS 10. Quando a aplicação foi realizada preventivamente, resultou em maior área foliar verde remanescente $\mathrm{e}$ menor desfolha (Figura 2), ao contrário da aplicação curativa onde a desfolha foi maior (Figura 1).

Na pulverização preventiva, a eficácia de controle da doença não permitiu distinguir os ingredientes ativos, exceto propiconazole que na dose recomendada apresentou pouca eficácia. Uma análise geral de diversos fungicidas mostra uma tendência dos maiores ganhos no rendimento estarem relacionados a aplicações preventivas entre os estádios $R_{1}$ e $R_{3}$. No caso da ferrugem da soja, a necessidade de aplicações preventivas mostra-se ainda mais importante, conforme já

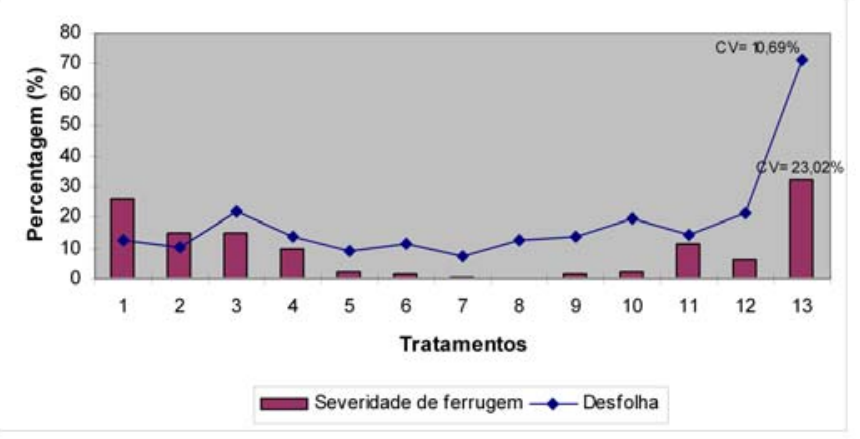

Figura 1 - Relação da severidade de ferrugem com a desfolha da cultivar RS 10 com aplicação curativa de fungicidas. Santa Maria, 2005.

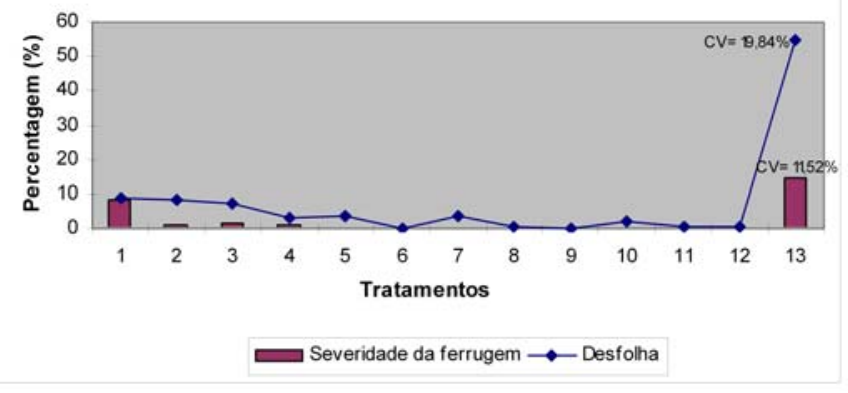

Figura 2 - Relação da severidade de ferrugem com a desfolha da cultivar BRS 154 com aplicação preventiva de fungicidas. Santa Maria, 2005. havia sido observado por Bromfield et al. (4) em que o aumento nos danos da doença a partir da floração é mais acentuado.

A aplicação dos fungicidas na cultivar RS 10 foi realizada no estádio $\mathrm{R}_{5.3}$, em caráter curativo, supostamente fora do momento ideal de controle, explicando a dificuldade de alguns ingredientes ativos controlarem eficientemente a doença, mesmo tendo sido aumentada a dose. Hartman et al. (9) verificaram o aumento da severidade da ferrugem durante o estádio fenológico de enchimento das vagens, o que torna ainda mais relevante o posicionamento antecipado de controle. Veiga et al. (19), verificaram redução significativa no controle quando a aplicação dos fungicidas foi realizada com presença de doença.

Quanto ao rendimento, observa-se que mesmo nas aplicações curativas sobre a cultivar RS 10, o ganho obtido foi superior ao observado na cultivar BRS 154 (Tabela 5). Este resultado caracteriza a responsividade varietal associada à aplicação dos fungicidas. A ausência de correspondência entre a reação de cada cultivar às doenças foliares e a resposta ao controle químico, tem sido observada na cultura da soja, e indica que as cultivares podem variar não somente devido à ação dos fungicidas, mas principalmente devido à capacidade fisiológica de resposta ao controle químico própria de cada cultivar (6).

Segundo Giordani (7) a determinação do estádio de desenvolvimento que permite a melhor expressão físiológica de cada cultivar é relevante no manejo das doenças foliares da soja. É possível que seja mais importante um correto posicionamento do controle químico em relação a cada cultivar associado ao estádio de aplicação que possibilite sua melhor resposta do que propriamente a escolha de um determinado ingrediente ativo, principalmente no caso de uma doença como a ferrugem, cuja taxa de progressão é elevada. Evidentemente que a associação de ingredientes ativos, na medida em que o estádio de aplicação for corretamente posicionado, torna vital para um controle eficaz da doença.

Os dados obtidos demonstram a importância de um número de aplicações adequado ao ciclo de cada cultivar, bem como às características relacionadas aos diversos grupos de ingredientes ativos e ao nível de inóculo presente no momento da aplicação, para que o controle da ferrugem da soja seja maximizado.

\section{REFERÊNCIAS BIBLIOGRÁFICAS}

1. Azevedo, L.A.S. de. Proteção Integrada de Plantas com Fungicidas: teoria, prática e manejo. São Paulo, 2001. 230pp.

2. Bianchini, F.G.; Campos, H.D.; Silva, L.H.C.P.; Silva, J.R.C.; Junior, J.N. Avaliação de triazóis no controle da ferrugem da soja. Fitopatologia Brasileira, Brasília, v.29, Supl., p.239, 2004. (Resumo).

3. Bromfield, K.R. Soybean rust. 1984. 63f. American Phytopathological Society. St. Paul, Minnesota. (Monograph n ${ }^{\circ} 11$ )

4. Bromfield, K.R.; Melching, J.S.; Kingsover, C.H. Virulence and aggressiveness of Phakopsora pachyrhizi isolates causing soybean rust. Phytopathology, v.70, p.17-21, 1980.

5. Caldwell, P.; Laing, M. Soybean rust - a new disease on the move. 2002. Disponível em: <http://www.saspp.org/archieved/tablesoybeanrust>. Acesso em 14 de março de 2005.

6. Dallagnol, L.J.; Balardin, R.S.; Ugalde, M.G. Reação de cultivares de soja a ferrugem da soja (Phakopsora pachyrhizi). In: Jornada Acadêmica Integrada, 19, 2004, Santa Maria. Anais. Santa Maria: UFSM, 2004. 1 CD-Rom.

7. Giordani, R. F. Controle de oídio e doenças de final e ciclo na cultura da soja. 2001. 57p. Dissertação (Mestrado em Agronomia) - Universidade Federal de Santa Maria, Santa Maria - RS.

8. Godoy, C.V.; Canteri, M.G. Efeitos protetor, curativo e erradicante de fungicidas no controle da ferrugem da soja causada por Phakopsora pachyrhizi, em casa de vegetação. Fitopatologia Brasileira, Brasília, v.29, p.97-101, 2004.

9. Hartman, G.L.; Wang, T.C.; Tchanz, A.T. Soybean rust development 
and the quantitative relationship between rust severity and soybean yield. Plant Disease, v.75, p.596-600, 1991.

10. Moura, E.A.C.; Juliatti, F.C.; Schiavetto, J.M.; Juliatti, F.C.; SOUSA, P.P. Efeito de sistemas de preparo de solo e aplicação de fungicidas no controle químico da ferrugem da soja. Fitopatologia Brasileira, Brasília, v.29, Supl. p.111, 2004. (Resumo)

11. Morel, W. Roya de la soja. Itapúa: Paraguay. Ministerio de Agricultura y Ganaderia. Subsecretaria de Agricultura, Dirección de Investigación Agrícola. Centro de Investigación Agrícola (CRIA) Capitan Miranda. Comunicado técnico: Reporte oficial. Serie Fitopatologica $n^{\circ} 1,2001$.

12. Ogle, H.J.; Byth, D.E.; Mclean, R. Effect of rust (Phakopsora pachyrhizi) on soybean yield and quality in South-eastern Queensland. Australian Journal Agriculture Research, v.30, p.883-893, 1979.

13. Oliveira, S.H.F. Época de aplicação de fungicidas no controle da ferrugem asiática (Phakopsora pachyrhizi) da soja. Fitopatologia Brasileira, Brasília, v.29 Supl. p.295, 2004. (Resumo)

14. Reis, E.M.; Bresolin, A.R., Ferrugem Asiática da Soja: Revisão e Aspetos Técnicos. In: Forcelini, C.A. et al. Doenças na Cultura da Soja. Aldeia norte Editora: Passo Fundo, 2004. p.55-70.

15. REUNIÃO DE PESQUISA DE SOJA DA REGIÃO SUL, 30. Indica- ções técnicas 2002. In: XXX Reunião de Pesquisa de Soja da Região Sul. Cruz Alta, 2002. 139p.

16. Santos, I.; Souza, R.N.; Giasson, N.F.; Fellipi, C.L. Eficiência de fungicidas aplicados em diferentes épocas no controle de ferrugem asiática da soja causada por Phakopsora pachyrhizi. Fitopatologia Brasileira, Brasília, v.29, Supl. p.80, 2004. (Resumo)

17. Silva, J.C.; Maia, G.L.; Meyer, M.C. Efeito do numero de aplicações de fungicidas no controle da ferrugem da soja. Fitopatologia Brasileira, Brasília, v.29, Supl. p.115, 2004. (Resumo)

18. Yorinori, J. T. Ferrugem asiática da soja (Phakopsora pachyrhizi): ocorrência no Brasil e estratégias de manejo. In: Encontro brasileiro sobre doenças da cultura da soja, 2, 2002. Aldeia Norte Editora, 2002. p.47-54.

19. Veiga, J.S.; Castro, R.M.; Paiva, S.B.; Vitti, A.J. Momento do início e intervalo de aplicação da mistura ciproconazol + Azoxistrobina na cultura da soja para controle da ferrugem asiática causada por Phakopsora pachyrhizi em diferentes regiões do Brasil. Fitopatologia Brasileira, Brasília, v.29, Supl. p.285, 2004. (Resumo)

20. Vitti, A.J.; Paiva, S.B.; Castrro, R.M.; Veiga, J.S.; Garcia, L. Efeito residual e curativo de fungicidas para o controle de ferrugem da soja (Phakopsora pachyrhizi). Fitopatologia Brasileira, Brasília, v.29, Supl. p.290, 2004. (Resumo) 